\title{
CONSTRUCCIÓN SOCIO CULTURAL DE LOS TERRITORIOS URBANOS. UNA INDAGACIÓN DESDE LA EDUCACIÓN
}

\author{
Alexánder Cely Rodríguez ${ }^{62}$
}

\section{RESUMEN}

El artículo presenta el proyecto de investigación que adelanta un grupo de docentes ${ }^{63}$ de Universidades de América Latina reunidos en la Redladgeo. El proyecto es una apuesta interinstitucional e internacional que busca identificar la concepción de ciudad contemporánea presente en los estudiantes que cursan carreras profesionales en educación (Pedagogía, Ciencias Sociales, Geografía). Se pretende comprender, analizar y comparar cómo ellos aprehenden las diversas espacialidades y temporalidades que denotan las formas de ser, estar e interactuar con la urbe latinoamericana desde su contenido material (arquitecturas, morfologías, funcionalidades) y su contenido simbólico (sentidos, narrativas, lenguajes, estéticas, prácticas, usos y apropiaciones).

El proyecto toma como escenario las ciudades de Bogotá y Medellín en Colombia, Sao Paulo, Goiânia e Ijui en Brasil, y Santiago de Chile. Estas ciudades han sido seleccionadas como referentes ya que son sedes de las Universidades y de los grupos de investigación que participan del proyecto. Uno de los resultados esperados de la investigación es la elaboración y presentación de una propuesta de lineamientos de política educativa para la enseñanza de la geografía en los respectivos países.

Palabras clave: Construcción socio - cultural, Territorios Urbanos y Educación.

\section{ABSTRACT}

This article presents the research project proposed and developed by a group of teachers from different universities in Latin America conforming the Redladgeo network. The project is an inter-agency and international commitment that seeks to identify the concept of contemporary city that students for professional careers in education (pedagogy, social sciences, geography) have. It is intended to understand, analyze and compare how they apprehend the spatial and temporal diversity which reflect ways of being, staying and interacting with the Latin American city from its material content (architectures, morphologies, functionalities) and its symbolic content (meanings, narratives, languages, aesthetics, practices, uses and appropriations).

62 Profesor de la Universidad Pedagógica Nacional, Bogotá D.C. - Colombia. Integrante Grupo de Investigación Geopaideia.

63 La propuesta plasmada es una construcción colectiva en la que participan los docentes: Elsa Amanda Rodríguez de Moreno, Alexánder Cely Rodríguez y Carlos Alberto Zambrano (UPN); Nubia Moreno Lache, Liliana Rodríguez Pizzinato y Jorge David Sánchez Ardila (UDFJC); María Raquel Pulgarín Silva y Alberto León Tamayo (UDEA); Sonia María Vanzella Castellar (USP); Lana de Souza Cavalcanti (U. GOIAS); Helena Copetti Callai (UNIJUI) y Marcelo Garrido Pereiria (UAHC). 
The project takes place in the cities of Bogotá and Medellin in Colombia, Sao Paulo, Goiânia, and Ijui in Brazil, and Santiago in Chile. These cities have been selected as benchmarks because they are sites of universities and research groups involved in the project. One of the expected results from this research is the development and presentation of educational policy guidelines for the teaching of geography in the respective countries.

Key words: socio - cultural construction, urban territories and education.

\section{INTRODUCCIÓN}

El proyecto de investigación es una apuesta interinstitucional e internacional que busca identificar la concepción de ciudad contemporánea presente en los estudiantes que cursan carreras profesionales en educación (Pedagogía, Ciencias Sociales, Geografía). De esta manera, se pretende comprender, analizar y comparar cómo ellos aprehenden las diversas espacialidades y temporalidades que denotan las formas de ser, estar e interactuar con la urbe latinoamericana desde su contenido material (arquitecturas, morfologías, funcionalidades) y su contenido simbólico (sentidos, narrativas, lenguajes, estéticas, prácticas, usos y apropiaciones).

Para alcanzar la finalidad expuesta, el proyecto toma como escenario las ciudades de Bogotá D.C. y Medellín en Colombia, Sao Paulo, Goiânia e Ijui en Brasil y Santiago de Chile. Estas ciudades han sido seleccionadas como referentes ya que son sedes de las Universidades y de los grupos de investigación que participan del proyecto. Así mismo, uno de los resultados significativos de la investigación es la elaboración y presentación de una propuesta de lineamientos de política educativa para la enseñanza de la geografía en los respectivos países.

Hasta la mitad del siglo XX la ciudad se pensó, en general, como una unidad homogénea y prácticamente indiferenciada en su interior, dentro de la concepción que de ella formaban sus habitantes. Pero en las últimas décadas esta visión ha venido cambiando tanto en la configuración material de la ciudad, como en la percepción de los ciudadanos y desde la mirada científica de sus estudiosos. Hoy la ciudad se concibe como una construcción institucional pero también como una construcción social, que hace que ella sea un caleidoscopio de imágenes de la ciudad. A la par la educación y la emergencia de las culturas urbanas han venido actuando protagónicamente como agentes de construcción social del espacio urbano, de apropiación de los lugares y de la expresión de lo que es la ciudad contemporánea y sus habitantes.

El proyecto de investigación "Construcción socio cultural de los territorios urbanos. Una indagación desde la educación" resulta principalmente del interés que la actual configuración de ciudades y ciudadanos plantea a los grupos de investigación, miembros de la Red Latinoamericana de Investigadores en Didáctica de la Geografía (REDLAGEO). El objetivo de este proyecto es realizar un estudio comparativo que permita identificar las convergencias y divergencias en las concepciones de los estudiantes que cursan una carrera pedagógica profesional a saber:

- Licenciatura en Educación Básica con énfasis en Ciencias Sociales de la Universidad Pedagógica Nacional.

- Licenciatura en Educación Básica con énfasis en Ciencias Sociales de la Universidad Distrital "Francisco José de Caldas". 
- Licenciatura en Ciencias Sociales de la Universidad de Antioquia.

- Carrera de Pedagogía y Licenciatura de la Geografía de la Universidad de Sao Paulo, Brasil.

- Licenciatura en Geografía de la Universidad Federal de Goiás, Brasil.

- Carrera de Pedagogía, Licenciatura en Geografía y Licenciatura en Historia de la Universidad de Ijuí, Unijuí, Brasil.

- Carrera de Pedagogía en Historia y Ciencias Sociales de la Universidad Academia de Humanismo Cristiano - Santiago de Chile, Chile.

\section{EL OBJETO}

\section{ESTADO DEL ARTE}

El estado del arte o balance bibliográfico inicial identifica tendencias y concepciones sobre la ciudad y los territorios urbanos; así como reflexiones sobre la formación ciudadana en la perspectiva de la enseñanza del espacio desde la geografía escolar; la cual es asumida para el presente proyecto, no solo por la naturaleza misma de sus pretensiones sino también por los intereses investigativos de los grupos que en ella participan.

\section{Ciudad y territorios urbanos}

La ciudad presenta diversas acepciones e interpretaciones en los campos del saber en tanto corresponde a un espacio producto de la acción humana, que involucra de hecho un acto cultural. Desde los lentes geográficos, es posible concebirla desde una proyección tridimensional porque deja ver elementos funcionales, culturales y físicos, que se entrelazan para constituir imágenes urbanas. En este aspecto tridimensional, el hombre como ser transformador de un espacio ejerce gran influencia sobre la ciudad, ya que él es quien la transforma a través del tiempo por medio del uso del suelo. Lo funcional, cultural y físico permiten detectar elementos fundamentales de una ciudad, que van desde su mismo emplazamiento hasta su expansión, teniendo en cuenta la distribución, dinámica y utilización del espacio urbano.

Imagen urbana que se complementa con la concepción teórica de Carter (1974) cuya aplicación permite hablar de la ciudad bajo dos grandes dimensiones: La ciudad en el área y la ciudad como área. Es decir la ciudad se constituye en un sistema de relaciones que se manejan al interior y al exterior de ella, evidenciando su dinámica y complejidad entre su estructura interna y las regiones cercanas. De esta manera la ciudad adquiere status e inicia un proceso de crecimiento y dinamicidad que lo convierten en un lugar complejo de estudio y comprensión, pero que demanda de su análisis para poder generar unas nuevas posibilidades de conocimiento. La ciudad se concibe como un compendio de múltiples y diversos elementos y categorías físicas, culturales y funcionales que llegan a establecer relaciones con espacios exteriores e interiores.

Es importante resaltar la acción del hombre en la ciudad ya que ella permite estructurar en ésta valores sociales, políticos y económicos por medio del establecimiento de funciones administra- 
tivas, residenciales, educativas, financieras, recreativas y comerciales que llevan a la denominada humanización del espacio; que en últimas es la relación de diálogo y pertenencia con el espacio a partir de la construcción socio - territorial y cultural del hombre. La ciudad, entonces evidencia una estructura urbana que es entendida como las diversas formas de especialización del suelo en zonas diferentes, teniendo en cuenta las características demográficas y sociales que existen.

Desde esta perspectiva la ciudad demuestra el aspecto macro estructural y micro estructural, es decir los aspectos que reflejan el juego de relaciones existentes en la ciudad evidenciados en la arquitectura, la estructura social, la concentración de servicios, los diversos sectores como el residencial, financiero e industrial y las relaciones socio-económicas que generan entre sí; sin obviar elementos tan importantes en la ciudad y en la percepción que de ella poseen sus habitantes, tales como nodos, hitos, bordes, sendas y cinturones comerciales que construyen la concepción individual de la ciudad.

La ciudad y los territorios urbanos se entienden también, por ejemplo, como recurso y como estrategia de vida; como espacio para la educación, como objeto para la creación y la transformación de valores encaminados a la existencia de dicha sociedad, y como un tejido cultural que puede comprenderse como resultado de un proceso activo de construcción simbólica de la realidad o como trama de significaciones compartidas.

Montañez argumenta que (1997, pp. 181-182) "independientemente de las aproximaciones que se hagan sobre la dimensión espacial, en relación con los humanos se pueden plantear una serie de principios geográficos, los cuales pese a ser simples y obvios no dejan de ser importantes. Estos principios son los siguientes:

1. Toda actividad humana se realiza en un espacio determinado,

2. Toda actividad humana requiere de un espacio mínimo para su ejecución, sin el cual es imposible llevarla a cabo,

3. Toda actividad humana requiere de un máximo de espacio para su realización, a partir del cual se puede hablar de un espacio sobrante,

4. Toda actividad humana realizada en un espacio determinado tiene siempre espacios vecinos,

5. la distancia entre puntos o lugares del espacio es con frecuencia un factor explicativo de significación de las relaciones entre ellos,

6. Cualquier porción de espacio geográfico es fuente de información,

7. El espacio es con gran frecuencia objeto de simbolización humana,

8. El espacio geográfico dirige el flujo de personas, bienes y servicios,

9. El espacio geográfico es el palimpsesto de la historia humana,

10. Cada porción del espacio geográfico tiene sus propios atributos físico-bióticos y sociales". 
En este panorama epistemológico, es pertinente precisar la importancia y postura del enfoque de la geografía humanística, la cuál es vista como una nueva manera de hacer y entender la geografía y considera al individuo como parte integrante fundamental de la explicación en ciencias sociales. A partir de 1960, el panorama geográfico encontró otro punto paradigmático cuando se desarrolla todo el sistema de la geografía de la percepción y las imágenes mentales.

El objetivo fundamental era integrar esta disciplina científica con otros campos del saber, específicamente con la psicología. Se parte de aceptar que el hombre es el principal elemento que modifica y complementa un espacio; por tanto lo esencial no es explicar el medio geográfico real, sino lo que percibe el hombre de acuerdo con sus expectativas, "Ya que la geografía del comportamiento y de la percepción pretendía responder a las cuestiones planteadas en él: preocupación por el medio y los problemas sociales, orientación hacia la planificación y reconocimiento de los geógrafos, así como el resto de los mortales, son personas con visiones y percepciones diferentes del mundo, y no observadores objetivos exentos de juicios de valor." (Estébanez, 1982:93). Entonces, es posible comprender que:

- Es viable interrelacionar diferentes elementos que permiten introducir el concepto y la categoría espacial de ciudad, referenciando su importancia para ser estudiada y particularmente comprendida como recurso y estrategia que da cuenta de la percepción que de ella se generan los actores del escenario urbano.

- La ciudad como recurso permite igualmente en los estudiantes y en todos los habitantes que reflexionen sobre este tema alcanzar competencias que les consentirán interactuar desde lenguajes diferentes en la ciudad, creando otras alternativas de ciudadanía y ciudadano urbano.

- El llevar a pensar la ciudad, a aprender en la ciudad, a aprender de la ciudad y aprender la ciudad (Trilla; 1970), potencia nuevas miradas que acercan al sujeto a comprender los lenguajes y expresiones de su lugar de vida, de sus territorios socio - culturales, lo que permite a su vez reflexionar, construir y de-construir las diversas formas de interactuar, acercarnos y vivir en y para la ciudad; formas que a su vez refrescan la concepción tradicional de la geografía y aportan elementos valiosos para proyectar otras concepciones, apuestas pedagógicas y didácticas de la geografía en la escuela.

\section{Espacio geográfico y formación ciudadana}

La ciudad en la mayoría de los escenarios educativos es desconocida como objeto de estudio, siendo difícil no sólo avanzar en la transformación de la concepción de la disciplina y del espacio, sino también y de manera particular en la formación de ciudadanos comprometidos con sus semejantes y con el espacio que ocupan, habitan y transforman, por lo general, sin la conciencia de ello y sin la adecuada proyección y planificación del mismo.

En tal sentido, es relevante la propuesta expuesta por Fernández Caso (2007) al exponer tres criterios fundamentales sobre los cuáles se debe pensar los temarios geográficos escolares que contemplan con gran énfasis lo urbano, e incorporarlos en apuestas didácticas afines que impulsen una geografía escolar diferente para las sociedades y territorios contemporáneos. Los criterios dan cuenta de una interesante reflexión por lograr una geografia de los ciudadanos, constituyéndose a su vez en una provocación para la enseñanza de la geografía. Corresponden a: 
1. Criterios lógicos expresados a través de los saberes escolares, en donde el campo de conocimiento geográfico demuestra un acumulado valioso y fundamental en cuanto a información, conocimientos y saberes espaciales, vitales en la escuela y en la comprensión de la geografía en general.

2. Criterios sociales latentes y necesarios en los programas de enseñanza geográfica ya que en éstos se evidencia el sentido social del espacio, es decir son los que permiten cimentar las bases para la formación ciudadana.

3. Criterios psicológicos que atañen directamente a la labor del docente en el aula de clase y en la escuela en general, provocando en los estudiantes una atracción significativa por el proceso de enseñanza y aprendizaje; este criterio es quizá el que mayor relevancia posee en tanto es la resultante de los dos anteriores, pero a su vez, es el que logra la incorporación de una nueva mentalidad sobre la concepción geográfica.

Desconocer criterios como los expuestos conduce a que la ciudad y lo geográfico sea entendido en algunos escenarios educativos como "un conglomerado de conflictos y problemáticas de dificil y en ocasiones imposible solución". De esta manera, no es visible la formación del pensamiento y actitudes ciudadanas que posibiliten asumir posición analítica y crítica, la cual se refleja en actitudes de convivencia y proposición ante las problemáticas sociales de la ciudad, del espacio geográfico en general y de las personas que interactúan en ella. Por esta razón, la concepción de la geografía escolar, de la geografía urbana, de la ciudad y de los territorios urbanos, puede y necesita cambiar significativamente hacia la recuperación del sujeto que la constituye, máxime si "Queremos demostrar que la enseñanza de la geografía proporciona un saber útil y relevante para la vida de los ciudadanos del siglo XXI. Y la enseñanza y el aprendizaje de la geografía se ocupan de esas cuestiones" (Souto, 1999: 21).

Se debe entonces, apostar por la construcción transversal de la formación ciudadana en los programas de geografía escolar; para que sea a su vez, viable articular el sentido y el ser del sujeto en la ciudad reflejado en la apropiación y utilización raciocinada de los diversos escenarios que conforman el espacio urbano tales como: la calle, el supermercado, el parque, los centros de servicios, las bibliotecas, etc., hasta la generación de actitudes que permitan entender y entenderse en la multiplicidad de sujetos que interactúan en el espacio, trascendiendo la misma temporalidad de la ciudad con una proyección a futuro en los contextos contemporáneos de las nuevas formas de territorialidad.

\section{Problema de indagación}

Desde la segunda mitad del siglo XX el reconocimiento social progresivo de los niños y jóvenes, ha permitido a éstos visibilizar diversas formas y elementos que intervienen en la construcción social de la ciudad contemporánea. Dichas dinámicas aunque están presentes en los procesos educativos, todavía no han sido investigadas y reconocidas desde el punto de vista curricular de la enseñanza de las ciencias sociales y la geografía.

Esta situación no sólo afecta a los estudiantes en su propósito de comprender la importancia de la construcción social del territorio urbano, sino a quienes tienen la responsabilidad de su formación, la elaboración de los proyectos de aula, los planes de área, los proyectos educativos; al igual que a quienes deben gestionar, decidir y poner en práctica las políticas educativas en materia de Ciencias Sociales y Geografía. 
Para resolver este desfase, el presente proyecto pretende conocer la manera cómo los jóvenes piensan, sienten, apropian, usan y dotan de sentido la ciudad contemporánea en Colombia, Brasil y Chile. Para ello, la investigación se orienta hacia la indagación de las prácticas individuales y colectivas en que se materializa la construcción social de la ciudad de los estudiantes de los programas pre graduales de Pedagogía, Ciencias Sociales y Geografía de las universidades participantes.

\section{Preguntas orientadoras}

- ¿Cuáles prácticas individuales y colectivas expresan la concepción de ciudad en los estudiantes de pregrado de Pedagogía, Ciencias Sociales y Geografía de las Universidades participantes?

- ¿Cuáles son los imaginarios de los estudiantes sobre la ciudad contemporánea?

- ¿Cuál es la concepción de ciudad contemporánea en los estudiantes?

- ¿De qué manera el conocimiento de las concepciones de ciudad en los jóvenes puede dinamizar la enseñanza de las Ciencias Sociales y la Geografía?

\section{Objetivos perseguidos}

- Realizar un estudio comparativo sobre las concepciones de ciudad que tienen los estudiantes de pregrado de los programas de Pedagogía, Ciencias Sociales y Geografía de las universidades participantes en el proyecto, con miras a reconocer los procesos de construcción sociocultural de los territorios urbanos involucrados.

- Establecer un análisis comparativo de los procesos de construcción socio-cultural de los territorios urbanos para los distintos estudiantes y ciudades que participan en la investigación.

\section{ALGUNAS APROXIMACIONES A LOS REFERENTES TEÓRICOS GEOGRAFÍA: CIUDAD Y TERRITORIOS URBANOS}

El espacio geográfico contemporáneo es cada vez más urbano, dinámico y contrastante; por lo mismo, pensar en una definición que considere todos, o la mayor parte de los elementos que lo constituyen es una labor inacabada. No obstante, puede entenderse como una construcción social y territorial que goza de facultades económicas, políticas, sociales y culturales, entre otras, motivadas por la sociedad que lo habita, transforma y dinamiza; y en donde los procesos históricos muestran cambios de la realidad socio - espacial e inciden en las funcionalidades, redes, relaciones y dinámicas de las áreas urbanas, tanto en su interior como con otras áreas o espacios geográficos sobre los cuáles influye o es influenciado.

La definición "clásica" asume la ciudad y el espacio urbano en general como un compendio de elementos físicos, culturales y funcionales, estableciendo relaciones con otros espacios. Zarate (1984) dice al respecto que "La ciudad es un espacio geométrico, social, económico y vivencial, también es un espacio físico que se localiza sobre un punto concreto de la superficie terrestre, y que se constituye y organiza con relación a un entorno cercano e inmediato y a otro más distante". Aún 
así, la dinámica de la ciudad lleva a contemplar no solo la identificación de sus características fundamentales, sino también incluir aspectos relacionados con la sociedad contemporánea y por ende con temáticas, problemas y vivencias urbanos y territoriales de la actualidad.

Una posibilidad para interpretar lo urbanizado puede basarse en la identificación y comprensión de dos perspectivas, relacionadas con los elementos constitutivos de la misma a saber: lo material y lo inmaterial.

La ciudad material refleja las construcciones concretas, los objetos que hacen parte de ella, emergentes en diversos momentos y circunstancias, así como las temporalidades que denotan la apropiación y transformación del espacio urbano. En tanto, la ciudad inmaterial refleja los símbolos, representaciones, ideas, ideales e imaginarios, haciendo que ésta no sea solo de presencia e impacto a través de una distancia concreta, sino que llegue más allá de sus propias fronteras. Es posible entonces reafirmar que, "Una de las mutaciones más importantes registradas desde finales del siglo XX son los cambios de y en la ciudad como forma territorial" ${ }^{44}$ (Blanco y Gurevich. 2006:72). Estas mutaciones de carácter múltiple, son evidentes de acuerdo con los contextos espaciales en dónde se desarrolla, existiendo así diversas manifestaciones de ciudad y por ende de ocupación, vivencia y apropiación de y en ella.

Las "nuevas formas de ser y expresión" de los espacios urbanos, generan clasificaciones espaciales que consideran no sólo los escenarios locales, sino también el impacto en ámbitos regionales, nacionales e incluso mundiales. Transformaciones urbanas que han sido marcadas con mayor fuerza en la última década del siglo XX y primeros años del siglo XXI, instaurando el empleo de conceptos y procesos como: metrópolis, metropolización y metápolis, entre otros.

Actuales manifestaciones urbanas afectan no solo la distribución espacial en términos de dinámica, expansión y contraste, sino también en la generación de "procesos dobles" reflejados tanto en las vivencias cotidianas de sus habitantes, como en las formas y relaciones de mundialización en las que se hallan inmersas, y por lo tanto en la manera como se configuran relaciones y diálogos con y desde la ciudad.

Es importante resaltar la acción del hombre en la ciudad, que suele expresarse como una territorialidad en el lugar y que permite estructurar en su espacio acciones y valoraciones, llevando a la apropiación y a la llamada "humanización del espacio" concreto y específico de la ciudad.

\section{EDUCACIÓN Y ENSEÑANZA DE LA GEOGRAFÍA}

Tradicionalmente la geografía ha sido entendida y asumida en contextos escolares como una ciencia encargada de la enumeración y descripción de los fenómenos físicos en la superficie terrestre, siendo relegada y marginada a una labor netamente de memorización mecánica de datos y lugares, olvidando su centro de estudio que es el espacio geográfico.

$64 \quad$ La propuesta de investigación hace una apuesta interesante al asunto de lo territorial no solo por la tendencia reciente que este concepto tiene en el marco de la reflexión geográfica, sino también porque esta categoría evidencia una triada interesante en los estudios sobre la ciudad, en tanto a través de ella es posible sustentar la articulación tridimensional de la ciudad si se considera: la morfología, la civis y la polis, todas latentes en el espacio urbano. 
Esta concepción es reafirmada, tanto en programas y currículos de diversas instituciones educativas, como también en el imaginario y referente social de las personas, que la instauran como la "ciencia" encargada de la descripción y elaboración de mapas; de este modo "La enseñanza de las Ciencias Sociales, particularmente de la geografía, en la educación básica ha sido blanco de una serie de polémicas en la que se duda de la importancia de esta área en la formación de los educandos, en su eficacia y en el aporte que proporciona a la sociedad y al espacio en que se vive" (Rodríguez, 2000:11)

En la práctica pedagógica, existen inconsistencias y contradicciones entre el discurso académico, la enseñanza y la práctica espacial de los docentes en la enseñanza de dicha disciplina, viéndose reflejado en el panorama escolar que en materia de educación geográfica no ha cambiado sustancialmente, a pesar de las reformas educativas de los últimos cincuenta años.

A pesar de este panorama, la geografía escolar ha ido transformando su concepción en la última década del siglo XX y primeros años del presente siglo producto de aportes didácticos y reflexiones epistemológicas, resultados de investigaciones e inquietudes de docentes - investigadores interesados en transformar su objeto de ser en la enseñanza; hecho que ha permitido en la actualidad, reconsiderar a la geografía como aquella disciplina que estudia e interpreta el espacio geográfico, cercano o lejano; por lo cual, busca comprender la interrelación del hombre con el espacio y detectar los factores y los elementos que influyen en la concepción de ese determinado espacio.

Un programa tradicionalista de enseñanza geográfica, desconoce o margina la lectura al espacio urbano incorporando estos ejes, en tanto el espacio solo corresponde a una especie de recipiente y que Souto llama a la reflexión cuando expone que: "En el caso de la geografía se ha generado un estereotipo que relaciona este estudio con un listado de nombres y descripciones de lugares" (Souto; 1999: 21). No obstante, y si se acude a nuevos campos y a concepciones contemporáneas de la disciplina, es viable construir una pedagogía del espacio, en la cual los niños, niñas y jóvenes reconozcan en éste, su escenario de constitución individual y colectiva, y en donde los lugares, datos, accidentes, relieve, cifras, y demás contenidos afines a la geografía, juegan un papel fundamental en tanto se conciben desde lo relacional, lo funcional y lo comprensivo y no en lo enumerativo como ha sido tradicional de la geografía en las escuelas. En consecuencia, estos ejes inciden en la formación espacial y ponen en juego los espacios geográficos, urbanos y citadinos contemplando una nueva mirada a dichos escenarios, a las formas como los seres humanos habitan, se apropian y coexisten en los lugares, a las maneras como se explotan y conservan los recursos espaciales, y a las alternativas para comprender el espacio en su complejidad. Complejidad que articula la concepción y relación entre lo cercano y lo lejano; las escalas de los lugares en donde las dimensiones espaciales juegan un papel fundamental para la identificación, comprensión y abstracción del espacio, y el aspecto de la vivencia y percepción desde la manera como es habitado el espacio y a su vez habita a las comunidades que en él se constituyen.

Esta reflexión lleva a pensar que la enseñanza del concepto de ciudad y en especial el fomento de habilidades espaciales que permitan re-configurar la formación de ciudadanos vinculados al mundo y a las ciudades contemporáneas, afronta retos, demanda transformaciones y no es una tarea con última palabra. Resulta importante entonces:

- Contribuir en la formación de ciudadanos, de manera que éstos puedan conocer, interpretar y en especial ser eficaces en su ciudad, por lo cual es importante enseñarla desde una acción 
pedagógica cotidiana en donde el reconocimiento y apropiación del lugar sean evidentes; es decir lograr comprender que el espacio es "... lugar de pertenencia con el cual todos los habitantes (mujeres, hombres, niños, niñas, ancianos, ancianas, minusválidos) se identifiquen, se sientan responsables y encuentren modos de participación y gestión, respeten las ideas de los otros y contribuyan con el desarrollo de políticas de igualdad" (Alderoqui, 2006:46)

- Apostar a la comprensión de la dinámica social y espacial que caracteriza el espacio urbano, y del cual son factibles múltiples alternativas para su estudio y futura planificación.

- Transformar la enseñanza fragmentada de la ciudad y de la geografía en general, de modo que sea posible desde la integralidad, reconocer las singularidades sin aislar la continuidad que la constituye.

- Reconocer en la discontinuidad entre el espacio vivido y el espacio pensado una posible y necesaria articulación, de manera que lo subjetivo, tan necesario en el estudio de la ciudad, aporte valiosos elementos para su comprensión

- Trascender los marcos legales de las políticas educativas plasmados, por ejemplo para el caso de Colombia, en los Estándares de Competencias Ciudadanas y en los Estándares de Ciencias, pretendiendo ahondar en terrenos y esfuerzos desde las vivencias y realidades locales, regionales y nacionales; apostando así por una construcción quizá más acertada de formación ciudadana a partir de la escuela.

\section{ESPACIO Y CULTURA}

La relación espacial y su vínculo con la cultura está marcada por procesos que atraviesa el individuo en cada una de las etapas de su desarrollo. Es así como se tiene en cuenta dos posturas, una acerca de la percepción y representación del espacio y la otra sobre la concepción del espacio geográfico.

En la concepción del espacio transcurren etapas como: la percepción y la representación. El espacio percibido se entiende como aquel espacio que resulta del contacto directo de un sujeto con un objeto específico de conocimiento; el espacio representado hace referencia a la evocación que el individuo realiza de un objeto que ya ha conocido y manipulado. Ahora bien, partiendo de esta visión, el individuo en ocasiones no establece diferencia entre percepción y representación, bien sea por patrones culturales o por patrones de índole cognitivo. "En algunos casos no se ha dado el salto entre percepción y representación..., esto es típico de muchas sociedades primitivas" (Piaget e Inhelder, 1956 citados por Harvey, 1983).

Por tal motivo la diferenciación entre percepción y representación es cada día más difícil y dispendiosa de elaborar. La geografía a lo largo de la historia ha tenido el problema del espacio geográfico como objeto básico de estudio. Desde los griegos la concepción del espacio y su afán por dominarlo llevaron al posterior desarrollo de diversos enfoques epistemológicos que de una u otra manera determinaron un concepto específico de espacio.

Estas concepciones fueron alteradas, por así decirlo, en 1960, cuando la geografía de la percepción permitió desarrollar una nueva mentalidad del espacio geográfico. El problema de la percep- 
ción y la representación del espacio cobran importancia fundamental: "La representación (el acto por el cual un sujeto piensa o imagina algo organizándolo conforme a categorías) interviene en efecto en toda realización humana de orden intelectual o estético."(Duborgel, 1981 citado por Torres y Rodríguez de Moreno, 1993:29).

El espacio representado, según Piaget, se expresa a través de tres grandes categorías: la topológi$\mathrm{ca}$, la proyectiva y la euclidiana. Se evidencia que la finalidad última de la percepción y representación del espacio es desarrollar el sentido de conocimiento y manipulación del espacio ocupado por el hombre. "La idea básica es que el hombre decide su comportamiento espacial, no es función del medio geográfico real, sino de la percepción que posee del mismo."(Capel, 1985:42).

Bruner (1970), expone una visión sobre la formación de concepto de espacio haciendo referencia a los procesos denominados enactivos, icónicos y simbólicos. Su principal aporte radica en que en ningún momento el individuo se aleja de su contexto cultural y social en el que se desarrolla.

Lo enactivo expresa acciones motrices relacionadas con actos repetitivos, hábitos autorregulados, temporales y secuenciales. Es decir, el hombre controla el espacio que ocupa por medio de su conocimiento y a través de la repetición de diversos actos que le garantizan dicho conocimiento. Lo icónico expresa la construcción de imágenes y esquemas espaciales, en donde lo simultáneo y lo figurativo equivalen a una representación imaginativa. Finalmente lo simbólico se convierte en un proceso complejo en el que la referencia, la categorización y la gramaticalidad, así como las propiedades comunicativas, expresan un desarrollo de una representación espacial.

La percepción y la representación del espacio tienen un gran valor porque no sólo enriquecen al individuo con una visión del mundo sino, como lo expresa Bruner, "llevan al ser humano, con sus bagajes de acción, imaginación y simbolismo, a comprender y dominar su mundo." (Bruner, 1970).

Si se analiza desde la relación espacio geográfico - educación y cultura, podemos determinar que el proceso de enseñanza - aprendizaje de la geografía debe ayudar a comprender el mundo en que vivimos (Calaf, 1997). Para ello, deben existir una serie de procedimientos precedidos por actividades que buscan dar respuesta generalmente a pequeños problemas. En la geografía, el proceso de enseñar - aprender se lleva a cabo con base en actividades que se derivan de la interacción humana en el espacio y las cuales varían en la relación espacio - tiempo.

¿Qué aprende una persona a partir de la experiencia del espacio? Pregunta pertinente en cuanto se tiene en cuenta que la estructuración de las ciudades no se ha dado en forma espontánea, por el contrario, esta obedece a las lógicas ideológicas predominantes. Y debemos suponer que estas lógicas logran incidir en los individuos pero no en forma directa y llana, sino que se da una amalgama de elementos que termina dando una identidad a cada una de nuestras ciudades.

¿Cómo se relaciona el espacio con las formas ideológicas? Para dar respuesta a este interrogante partimos de la idea de que "...el espacio humano en general - y no solamente el espacio urbano- ha sido significante" (Barthes; 2003:12) En este sentido tenemos un espacio físico compuesto por diversos elementos, distribuidos y en un entramado de complejas relaciones que ha sido tomado por diversas posturas geográficas como un espacio objetivo. Por lo cual su estudio ha estado regido por modelos que tratan de explicitar relaciones también objetivas. 
Sin embargo, vemos que las formas de habitar y de ser en el espacio tienen un fuerte componente subjetivo. Este componente se forma en imágenes las cuales se definen como "...la significación vivida por oposición completa a los datos objetivos" (Barthes; 2003:12). Aquí cabría una distinción bastante problemática en la medida en que se introduce un elemento clave para la discusión, esta distinción es la que se hace entre unos procesos que se suscitan a nivel macro.

Tal vez Marc Augé nos arroje pistas cuando define esta situación como "sobremodernidad", entendida como la "superabundancia de acontecimientos" (Augé; 2004:34) Es importante anotar que el término acontecimiento tenía un mayor uso en ciencias cuyo eje central estaba determinado por la temporalidad, pero este concepto, el de "sobremodernidad" también es posible concebirlo para lo espacial. Y esto es así en la medida en que se ha dado un "achicamiento del planeta" y en forma simultánea las fronteras se han ampliado. La reducción ampliación del mundo implica un cambio en la escala con la que se había imaginado el mundo; así como la "...multiplicación de las referencias imaginadas e imaginarias..." (Augé; 2004:40).

Esta multiplicación de referencias está inmersa en la idea de la construcción de universos simbólicos que elaboran los individuos en sus contextos sociales, políticos, culturales y económicos. Entonces es posible observar un complejo entramado de relaciones que conllevan a que cada individuo interactúe con su entorno, tanto inmediato como lejano, y le permita elaborar imágenes que serán usadas para el conocimiento y el reconocimiento de espacios y lugares.

Quizá sea esta diferencia en el tiempo de permanencia lo que lleva a Marc Augé a definir los "No-lugares" la cual es una idea bastante interesante para la geografía, pues la preocupación se había centrado en la precisión de qué era un lugar y su diferencia con el espacio5. Así es como el no-lugar "no es un espacio de identidad", no es relacional ni histórico (Augé; 2004:83).

La existencia de los "No-lugares" es concomitante con la de los lugares, en consecuencia son espacios físicos cuya presencia está presente en los espacios urbanos de nuestras ciudades. Pero que se han constituido o mejor aún se han construido para transitar, para ir de un lugar a otro, pero no para permanecer. Llevando la discusión hacia hechos más concretos esto se traduce en los problemas de la movilidad en ciudades como Bogotá. Las vías se amplían en forma continua para que aumente la movilidad, la permanencia es sinónimo de caos, socialmente se valora como negativo el hecho de permanecer. Los recorridos se miden en términos de tiempo, a menor tiempo en los recorridos es posible una mejor calidad de vida, aunque irónicamente esta calidad de vida es por no permanecer ni tejer relaciones con mayor durabilidad. Por tanto, Es necesario continuar con la reflexión sobre el papel que desempeña la cultura en un contexto global, local y escolar, sobre todo para la construcción de sentido en la enseñanza de las Ciencias Sociales.

\section{METODOLOGÍA Y DELIMITACIÓN DE LA INVESTIGACIÓN}

El proyecto de investigación se sustenta en un trabajo que articula el saber geográfico y su enseñanza, la cultura, la ciudadanía y la formación ciudadana y la percepción e imágenes de ciudad y de territorios urbanos que poseen los estudiantes sujetos - objetos de la investigación, respaldados teórica y metodológicamente en la geografía humanística.

El proyecto corresponde a un estudio comparativo que acude al método cualitativo - interpretativo en donde se rescatan diversas categorías de análisis y se introduce la imagen y percepción de 
la ciudad como instrumento fundamental para la comprensión de las diversas formas como ésta es leída por los sujetos.

La investigación de tipo cualitativa - interpretativa es pertinente para aproximarse al estudio y comprensión de los fenómenos sociales, en la medida que reconoce la particularidad y la experiencia de los sujetos en el espacio; así mismo, potencia posibilidades para interpretar la realidad y los contextos socio - culturales en sus variadas manifestaciones desde lo que puede denominarse una hermenéutica del espacio ${ }^{65}$.

De igual forma el proyecto metodológicamente se respalda en la articulación existente entre espacio y cultura en la medida que relaciona y a su vez interpreta la distinción entre sujeto natural, sujeto urbano y sujeto cultural. La relación planteada a su vez está en concordancia con la semiótica general que considera al mundo como un texto y de la comprensión e interpretación de dicho texto se abre paso a la significatividad del mundo, para el presente proyecto el mundo corresponde a la categoría espacial de ciudad.

El proyecto determina las siguientes categorías de análisis:

- Ciudad

- Territorios urbanos

- Percepción e imagen de la ciudad

- Cultura

- Educación

Como técnicas a emplear en la investigación se considerará:

- Mapas mentales

- Historias de vida

- Grupos focales

- Observación etnográfica

- Itinerarios por la ciudad

- Relatos individuales y colectivos de ciudad, entre otros.

La población objeto de estudio corresponde a estudiantes, hombres y mujeres de diferente edad y estrato socio - económico - de los diversos semestres del programa de Licenciatura en Educación Básica con Énfasis en Ciencias Sociales de la Universidad Pedagógica Nacional, Bogotá D.C., Colombia.

65 “... el mundo es inteligible en virtud de la acción humana sobre éste, que es prioritario caracterizar y comprender la experiencia ordinaria de los seres humanos como seres viviendo en el mundo, objetivo que se puede lograr mediante la hermenéutica. Este argumento es de gran trascendencia para la geografía pues valida la importancia de regiones geográficas como el hogar, el lugar de trabajo, en fin aquellas en las que se da la relación entre el ser y el espacio... La geografía es desde este punto de vista, experiencia, vivencia y conciencia intencional de espacio y de lugar... una hermenéutica del espacio y del lugar vividos cotidianamente por los seres humanos (Tuan, 1977)". (Delgado; 2003:105). 


\section{BIBLIOGRAFÍA BÁSICA DE LA INVESTIGACIÓN}

Alderoqui, S. (2006). Enseñar a pensar la ciudad. En Alderoqui, S. y Penchansky, P. Ciudady ciudadanos. Aportes para la enseñanza del mundo urbano. Buenos Aires: Paidós Editores. p.p. 33 - 63.

Alessandri, A. F. (org.) (2004). A geografia na sala de aula. São Paulo: Contexto.

Augé, Marc (2004). Los No-lugares, espacios del anonimato. Barcelona: Gedisa.

Araya, F. y González, M. (Editores) (2009). Presente y futuro de la educación geográfica en Chile. La Serena: Universidad de la Serena.

Barthes, R. (2003). Semiología y urbanismo. En Revista Pre-til Nº1. Abril-junio. Bogotá D.C.: Universidad Piloto de Colombia.

Benejam, P. y PAGES, J. (1997). Enseñar y Aprender Ciencias Sociales, Geografia e Historia en la educación secundaria. Barcelona: Iber.

Blanco, J. y Gurevich, R. (2006). Una geografía de las ciudades contemporáneas: nuevas relaciones entre actores y territorios. En Alderoqui, S. y Penchasky, P. Ciudad y ciudadanos. Aportes para la enseñanza del mundo urbano. Buenos Aires: Paidós. pp. 67 - 91.

Borja, J. (2003). La ciudad conquistada. Madrid: Alianza.

Bruner, J. (1970:1980). Investigaciones sobre el desarrollo cognitivo. Madrid: Pablo del Río.

Calaf, R. et al (1997). Aprender a enseñar geografia. España: Oikos-tau.

Callai, H.C. (Organizadora) (2011). Educao geográfica. Ijuí: Unijuí.

Capel, H. y Urteaga L. (1985). Las Nuevas Geografias. Barcelona: Salvat.

Castellar, S. y Vilhena, J. (2010). Ensino de Geografia. Sao Paulo: Cengage.

Castellar, S. (2005). Educacao geográfica. Teorias y práticas docentes. São Paulo: Contexto

Carter, H. (1972). El estudio de la Geografia Urbana. Madrid: Instituto de Estudios de Administración Social.

Castrogiovanni, A.C. et al. (1998). Geografia em sala de aula, práticas e reflexões. Porto Alegre: UFRGS.

Cavalcanti, L. et al (Organizadores) (2011). Producao do conhecimento e pesquisa no ensino da geografia. Goiania: PUC.

Cavalcanti, L. (2010). Geografia, escola e construção de conhecimentos. São Paulo: Papirus.

Cavalcanti, L. (2008). A geografia escolar e a cidade. São Paulo: Papirus. 
Cely, A. y Moreno, N. (2008). Cotidianidad y enseñanza geográfica. Bogotá D.C.: Grupo Geopadeia.

Delgado, O. (2003). Debates sobre el espacio en la geografia contemporánea. Bogotá, D.C: Universidad Nacional de Colombia.

Doin de Almeida, R. (Coordinadora) (2011). Novos rumos da cartografia escolar. São Paulo: Contexto.

Estébanez, J. (1983). Tendencias y problemática actual de la geografia. Barcelona: Cincel.

Fernández, M. V. y Gurevich, Raquel (2007). Geografia. Nuevos temas, nuevas preguntas. Buenos Aires: Editorial Biblos.

Fernández, M. V. (Coordinadora) (2007). Geografia y territorios en transformación. Nuevos temas para pensar la enseñanza. Buenos Aires: Noveduc.

Garrido, M. (Editor) (2009). La espesura del lugar. Reflexiones sobre el espacio en el mundo educativo. Santiago de Chile: Universidad Academia de Humanismo Cristiano.

Harvey, D. (1977). Urbanismo y Desigualdad Social. Barcelona: Siglo XXI.

Harvey, D. (1983). Teorias, leyes y modelos en geografia. Madrid: Alianza.

Kaercher, N. (2007). Desafios e utopias no ensino de geografia. Santa Cruz do Sul : Edunisc.

Lynch, K. (1960). La Imagen de la Ciudad. Buenos Aires: Infinito.

Moreno, N. y Cely A. (Compiladores) (2011). Ciudades leídas, ciudades contadas. Bogotá D.C.: UDFJC.

Ministerio de Desarrollo Económico (1995). Ciudades y Ciudadanía. La Politica Urbana del Salto Social. Bogotá D.C.: Presencia.

Ministerio de Educación Nacional (2004). Formar para la ciudadanía si es posible. Estándares de competencia en formación ciudadana. Bogotá D.C.

Mockus, A. (2004). ¿Por qué competencias ciudadanas en Colombia? En: Al Tablero. Febrero-marzo 2004. Ministerio de Educación Nacional. Bogotá D.C.

Montañez, G. (2001). Razón y pasión del espacio y el territorio. En Varios Autores (compilación) Espacio y territorios. Razón, pasión e imaginarios. Bogotá D.C.: Universidad Nacional de Colombia.

Pontuschka, N. El al (2009). Para ensinar e aprender geografia. São Paulo: Cortez.

Rodríguez, J. (1999). El Palimpsesto de la ciudad. Ciudad Educadora: Un discurso para la democracia y la modernidad. Armenia: Fundesco.

Rodríguez de Moreno, E. A. (2000). Geografia Conceptual. Bogotá: Tercer Mundo. 
Rodríguez, L. (2007). Una geografia escolar (in)visible. Bogotá D.C.: UDFJC.

Romero, J. L. (2009). La ciudad occidental. Buenos Aires: Siglo veintiuno.

Santos, M. (2000). La naturaleza del espacio. Técnica y tiempo. Razón y emoción. Barcelona: Ariel.

Scheneier, G. (2006). Aportes para la enseñanza del mundo urbano. En Alderoqui, S. Ciudad y ciudadanos. Aportes para la enseñanza del mundo urbano. Buenos Aires: Paidós, pp. 143 - 168.

Silva, Armando (1992). Imaginarios Urbanos. Bogotá D.C.: Tercer Mundo.

Souto, X. M. (1998). Didáctica de la geografia. Barcelona: Del Serbal.

Straforini, R. (2008). Ensinar geografia. São Paulo: Annablume.

Tonini, I. M. ET al (2011). O ensino da Geografia e suas Composicoes Curriculares. Porto Alegre: UFRGS.

Torres de Cárdenas, R. C. y Rodríguez de Moreno E. A. (1993). La concepción espacial en niños de segundo grado. En Memorias del Seminario Regional de investigación y docencia de la geografia. Tulúa: Universidad Central del Valle.

Vasco, C. (1990). Pedagogía e Interacción Social. En Díaz, M. y otros. Pedagogía, Discurso y Poder. Bogotá D.C.: Nueva América.

Zarate, A. (1984). El mosaico urbano. Madrid: Cincel.

Zarone, G. (1993). Metafisica de la Ciudad. Pre-textos. España: Universidad de Murcia.

Artículo recibido 21 - 09 - 10. Aprobado $26-11-10$. 